\title{
PERANCANGAN SISTEM PENGGAJIAN GURU DAN KARYAWAN DI SDIT INSAN MANDIRI DEPOK
}

\author{
Firda Aldin', Tria Hadi Kusmanto ${ }^{2}$ \\ Program Studi Informatika, Fakultas Teknik dan Ilmu Komputer, Universitas Indraprasta PGRI \\ Jalan Raya Tengah No 80, Kelurahan Gedong, Pasar Rebo, Jakarta Timur \\ Firdaaldin18@ gmail.com ${ }^{1}$, triahadikusmanto@yahoo.com ${ }^{2}$
}

\begin{abstract}
Abstrak
Perkembangan teknologi sekarang ini semakin beragam, terutama dalam sebuah instansi atau perusahaan. Salah satunya yaitu sistem penggajian karyawan. Penelitian ini bertujuan untuk menganalisis sistem penggajian di SDIT Insan Mandiri Depok yang masih banyak kekurangan karena menggunakan sistem manual, sehingga dapat menghasilkan aplikasi yang memudahkan pekerjaan admin dalam memproses penggajian setiap bulannya. Sistem penggajian yang diusulkan mengacu pada jumlah kehadiran, transport dan uang makan sesuai jabatan guru dan karyawan. Sistem penggajian dibangun menggunakan metode R\&D (Research and Development) untuk menggantikan sistem lama dengan sistem baru yang terkomputerisasi dan telah lulus serangkaian uji coba. Pengumpulan data dilakukan dengan melakukan wawancara, observasi langsung, serta studi kepustakaan sebagai acuan dalam perancangan sistem yang baru. Hasil dari penelitian yaitu sebuah aplikasi penggajian berbasis desktop yang lebih efisien, mudah digunakan dan jauh dari kesalahan yang sering dilakukan manusia.
\end{abstract}

Kata Kunci: Aplikasi, sistem penggajian, guru, karyawan, R\&D

\begin{abstract}
The development of technology is increasingly diverse, especially in an agency or company. One of them is the employee payroll system. This research aims to analyze the payroll system at SDIT Insan Mandiri Depok which is still many shortcomings due to the use of manual system, so that it can produce applications that facilitate admin work in processing payroll every month. The proposed payroll system refers to the number of attendances, transport and meal money according to the positions of teachers and employees. The payroll system was built using the $R \& D$ (Research and Development) method to replace the old system with a new computerized system and has passed a series of trials. Data collection is done by conducting interviews, direct observation, and literature studies as a reference in the design of the new system. The result of the research is a desktop-based payroll application that is more efficient, easy to use and far from the mistakes that humans often make.
\end{abstract}

Keyword: Application, payroll system, teacher, employee, $R \& D$

\section{PENDAHULUAN}

SDIT Insan Mandiri Depok merupakan suatu yayasan sekolah Islam yang belum lama ini didirikan. Di sekolah tersebut belum terdapat sistem yang bisa membantu para pegawai untuk mengerjakan pekerjaannya. Semua sistem di sekolah masih dilakukan secaa manual. Salah satunya adalah sistem penggajiannya. Sistem penggajian nya masih dilakukan secara manual dengan menghitung jumlah kehadirannya atau berdasarkan status guru, gaji pokok, dan tunjangan. Keluar nya slip gaji juga selalu lambat karena penghitungan gaji yang dilakukan secara manual masih sering terdapat kekeliruan penghitungan. Untuk itu dibutuhkan sistem yang dapat mempermudah dalam penghitungan gaji dan absensi di sekolah tersebut. Berdasarkan latar belakang tersebut, maka peneliti berkeinginan untuk melaksanakan penelitian di SDIT Insan Mandiri Depok yang berhubungan dengan sistem penggajian di sekolah tersebut.

Penelitian ini bertujuan untuk merancang suatu sistem penggajian guru dan karyawan yang lebih terstruktur dan terkomputerisasi pada SDIT Insan Mandiri Depok, mempermudah pekerjaan petugas serta mempermudah guru dan karyawan untuk mengetahui rincian dari penghasilan yang 
diterima setiap bulannya. Penelitian ini menghasilkan sebuah aplikasi penggajian berbasis desktop yang lebih efisien, mudah digunakan dan jauh dari kesalahan yang sering dilakukan manusia.

\section{PENELITIAN RELEVAN}

Penelitian yang pernah dilakukan oleh Gumilar mengenai "Perancangan Sistem Administrasi Penggajian Guru dan Karyawan di SDIT Al-Muhajirin" menggunakan pendekatan deskriptif kualitatif berdasarkan pengumpulan data melalui observasi, wawancara dan dokumentasi. Selain itu Gumilar menggunakan alat bantu perancangan diagram alur data dan bahasa pemrograman Java dengan database mysql untuk mengelola data yang ada agar dapat terselesaikan secara efektif dan efisien sehingga dapat membantu kinerja pihak SDIT Al-Muhajirin (Ramadhan, 2016).

Nurseha dalam penelitiannya, merancang Sistem Aplikasi Penggajian Guru/Karyawan dan Administrasi pada TK Az-Zahra menggunakan metode grounded yaitu metode penelitian berdasarkan fakta dan menggunakan analisis perbandingan yang bertujuan untuk mengadakan generalisasi empiris, menetapkan konsep, membuktikan teori, mengembangkan teori. Setelah melakukan penelitian Nurseha menemukan kurangnya sumber daya manusia yang paham mengenai informasi Perancangan Sistem Aplikasi Penggajian Guru/Karyawan dan Administrasi pada TK AzZahra (Nurseha, 2016).

Sistem Informasi Penggajian yang dapat mempermudah proses pendataan penggajian di SMP Kebonagun (Saputra \& Bukhori, 2014), metode yang digunakan dalam penelitian ini dengan melakukan observasi, wawancara, studi pustaka, analisis, perancangan sistem informasi, dilanjutkan dengan pembangunan sistem informasi dan selanjutnya adalah uji coba.

Penelitian yang dilakukan oleh Tituk dan Indah menghasilkan sebuah sistem informasi pengolahan data gaji yang memberikan keakuratan data dan kecepatan pebuatan laporan yang berhubungan langsung dengan keuangan untuk data penggajian para pegawai.(Hermawan \& Wardati, 2016).

Penelitian yang dilakukan oleh Christian dan Rita, menghasilkan program yang dapat menunjang proses penggajian di Perusahaan tersebut, agar terhindar dari kesalahan yang dapat mengganggu jalannya usaha. Metode yang digunakan dalam penelitian ini adalah dengan observasi, wawancara, dan studi pustaka. Peneliti menggunakan Microsoft Visual FoxPro 9.0 sebagai bahasa pemrograman dan DBMS sehingga dapat membuat program yang lebih familiar untuk pemakai (user) (Haryadi \& Arifin, 2016).

\section{METODE PENELITIAN}

Peneliti menggunakan metode penelitian $\mathrm{R} \& \mathrm{D}$ (Research and Development) mengembangkan sistem penggajian pada SDIT Insan Mandiri Depok. Penelitian ini diawali dengan adanya permasalahan yang membutuhkan pemecahan dengan suatu produk tertentu. Masalah dalam penelitian ini adalah sistem penggajian yang masih menggunakan cara manual, sehingga akan dikembangkan sistem yang lebih efektif untuk menggantikan sistem yang lama. Setelah itu dilakukan pengujian terhadap sistem baru. Apabila sudah tidak terdapat kesalahan dalam sistem tersebut dan tidak perlu dilakukan revisi atau perbaikan, maka sistem tersebut sudah dapat digunakan secara optimal dan dapat dipertanggungjawabkan. Langkah-langkah pengembangan sistem : 


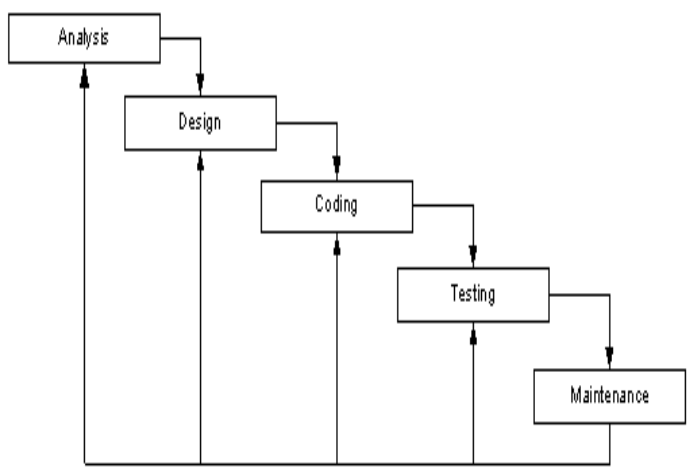

Gambar 1. Waterfall

\section{HASIL DAN PEMBAHASAN}

\section{Diagram Konteks Sistem yang Diusulkan}

Berikut adalah gambaran diagram konteks sistem Penggajian Guru dan Karyawan di SDIT Insan Mandiri. Hanya ada satu proses untuk input/output yang dilalui seluruh entitas (admin, bendahara, karyawan, guru, dan kepala sekolah).

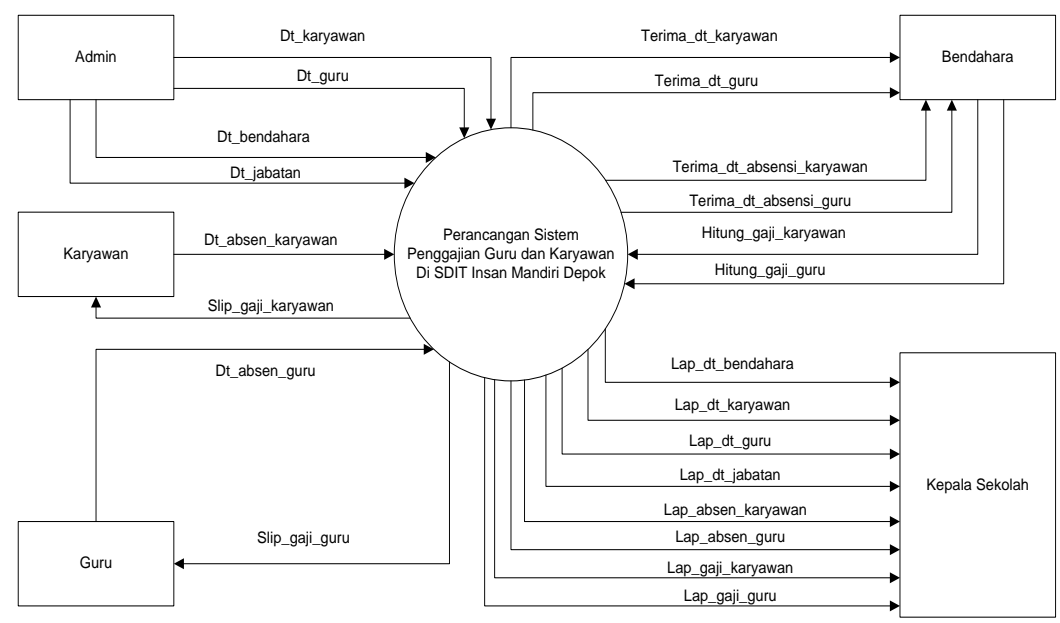

Gambar 2. Diagram Konteks Sistem Diusulkan

\section{Diagram Nol Sistem yang Diusulkan}

Berikut adalah gambaran diagram nol sistem Penggajian Guru dan Karyawan di SDIT Insan Mandiri Depok yang merupakan penjabaran dari diagram konteks. Terdapat 9 proses yang diusulkan yaitu proses pendataan karyawan, pendataan guru, pendataan bendahara, pendataan jabatan, absensi karyawan, absensi guru, penggajian karyawan, penggajian guru, dan laporan. 


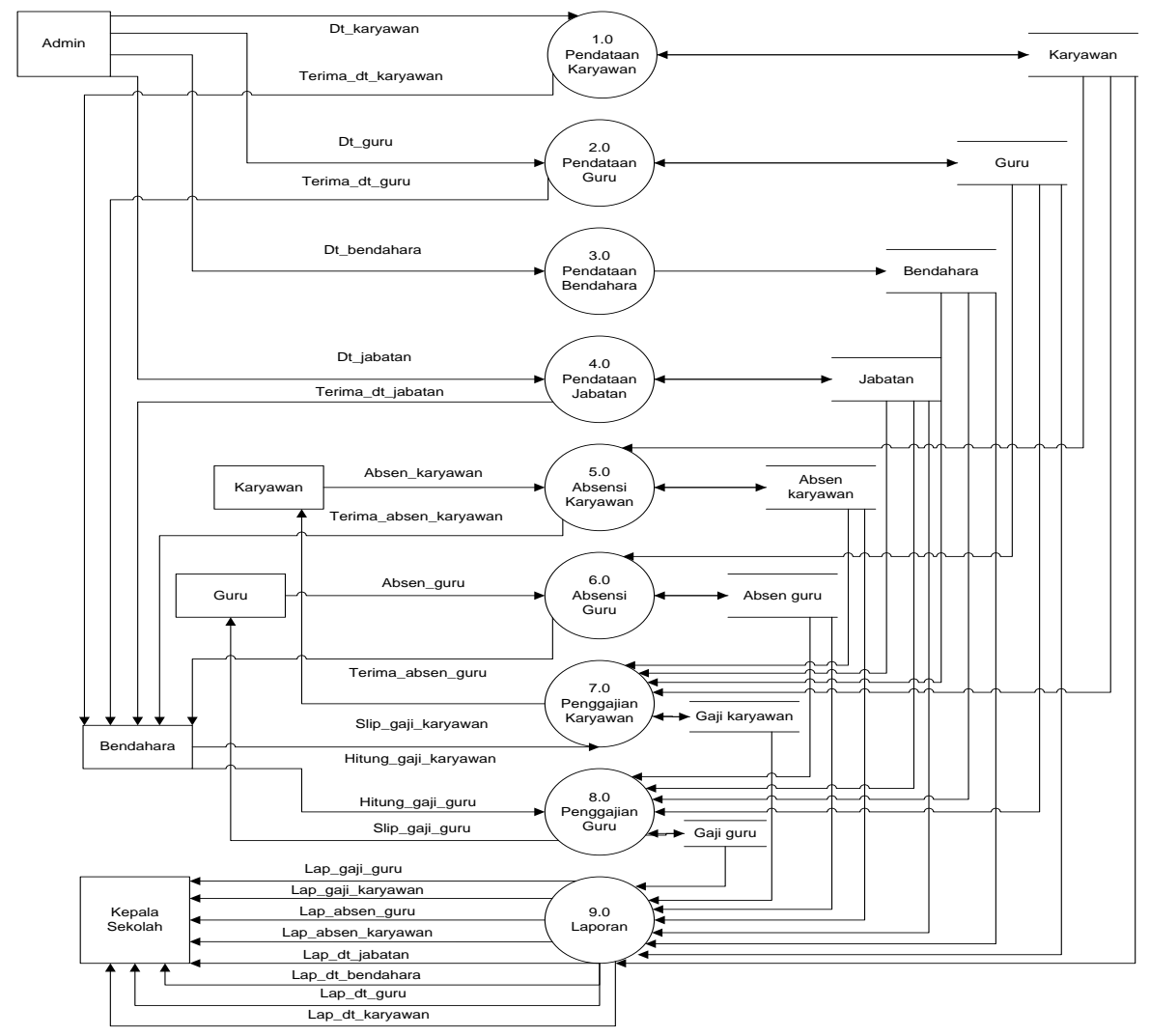

Gambar 3. Diagram Nol Sistem Diusulkan

ERD (Entity Relationship Diagram)

Berikut merupakan diagram yang menunjukkan hubungan antar data dalam basis data. Diagram berikut menggambarkan alur penggajian karyawan, dari mulai pendataan guru dan karyawan, jabatan, absensi hingga proses penggajian guru dan karyawan. 


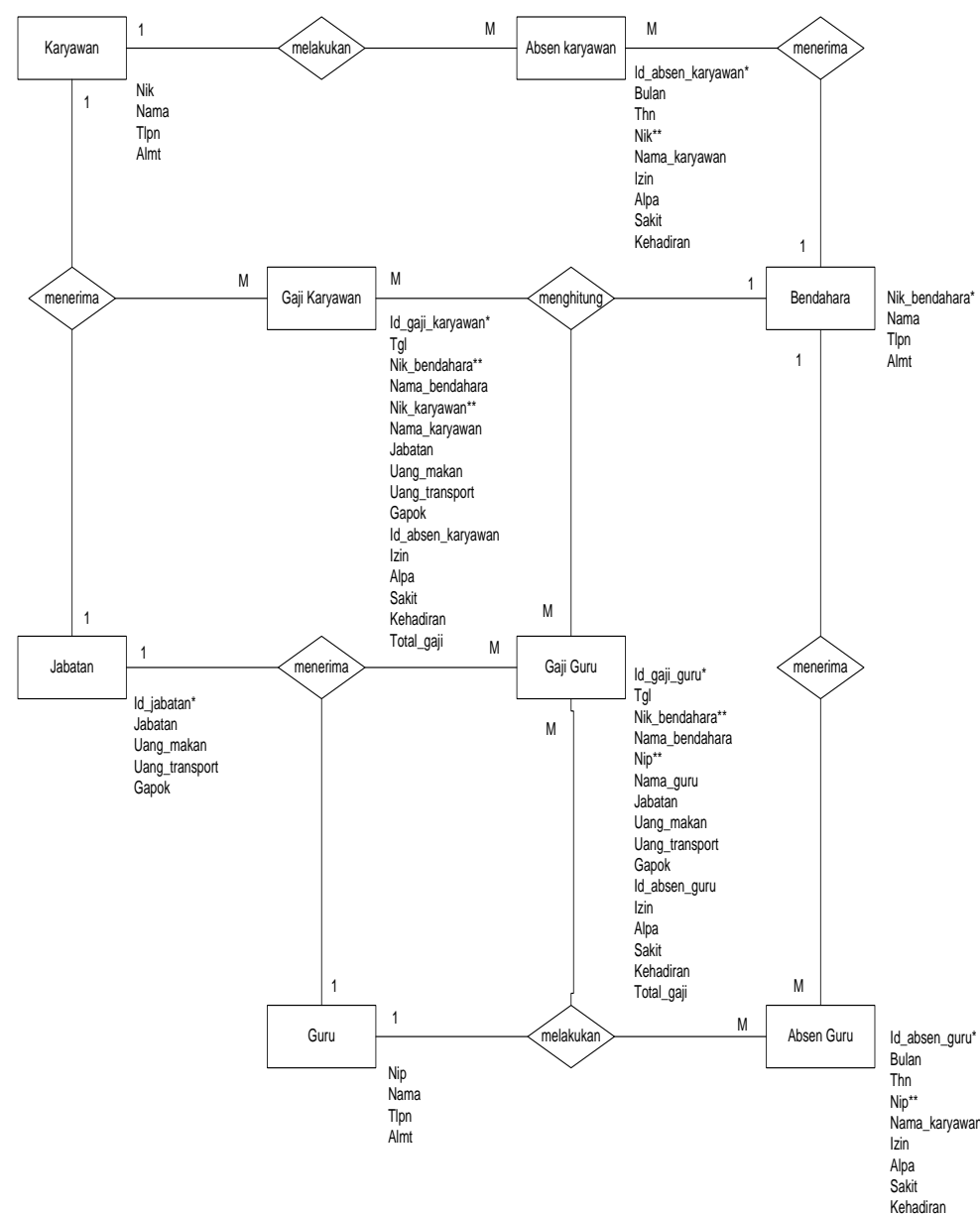

Gambar 4. Entity Relationship Diagram

\section{Tampilan Aplikasi Sistem}

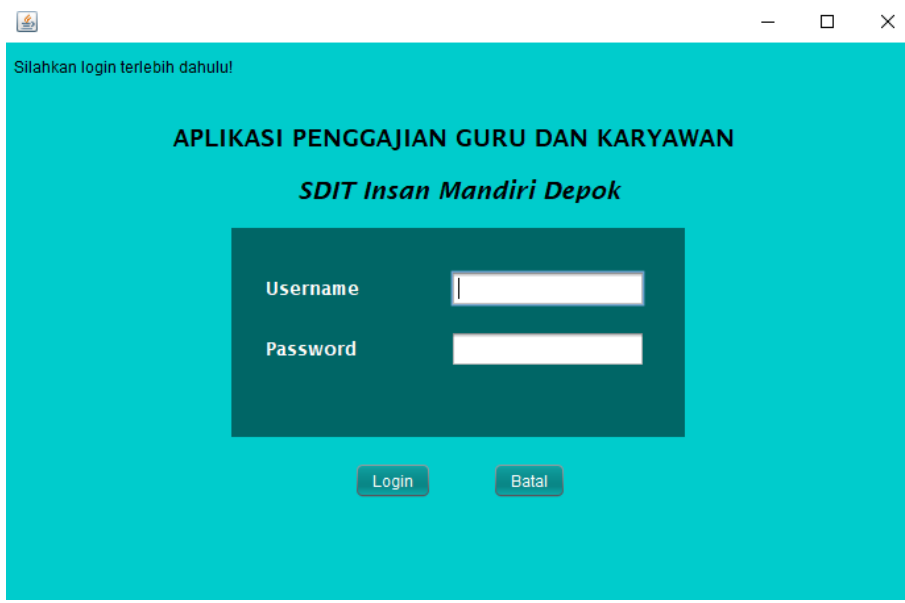

Gambar 5. Tampilan Form Login

Tampilan form login ini muncul di awal saat pengoperasian aplikasi penggajian untuk diisi oleh admin sebagai user. Masukkan username dan password yang sesuai dengan hak akses supaya bisa mengoperasikan aplikasi penggajian guru dan karyawan username dan password sesuai, maka akan masuk ke tampilan Menu Utama. 


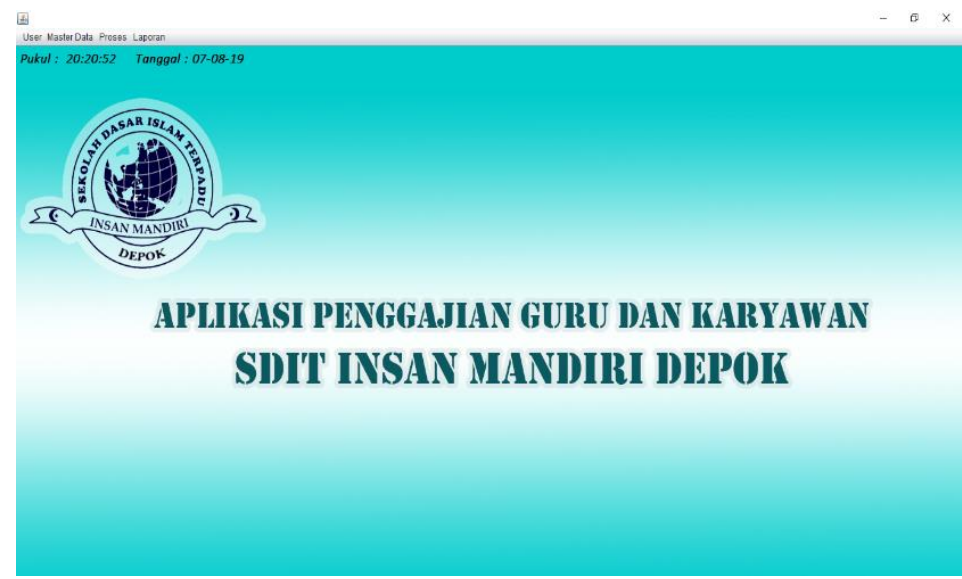

Gambar 6. Tampilan Menu Utama

Tampilan menu utama ini terdapat beberapa menu yaitu user (untuk logout akun), master data (berisi submenu pendataan guru, karyawan, jabatan, dan bendahara), proses (berisi submenu absensi guru dan karyawan, penggajian guru dan karyawan), dan laporan yang berisi output semua data input di master data dan transaksi, serta untuk cetak payslip.

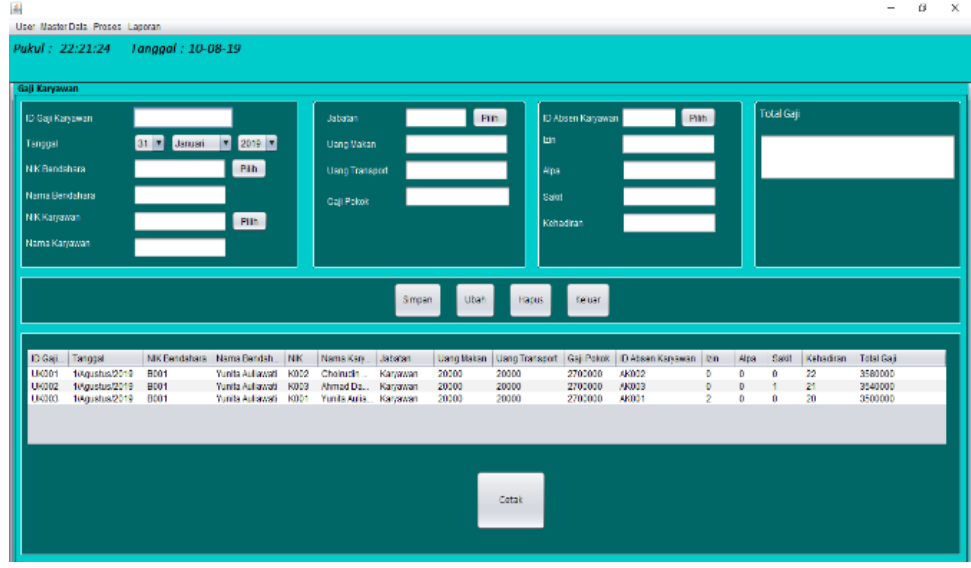

Gambar 7. Tampilan Form Gaji Karyawan

Tampilan form gaji karyawan ini, user dapat melakukan input data, mengubah, menghapus dan menampilkan data gaji karyawan. Terdapat inputan id gaji karyawan, tanggal, nik bendahara (klik button "Pilih" untuk mencari dari tabel bendahara, nama bendahara (akan otomatis terisi jika nik sudah dipilih), nik karyawan (klik button "Pilih" untuk mencari dari tabel karyawan) nama karyawan (otomatis terisi jika nik karyawan sudah dipilih), jabatan (klik button "Pilih" untuk mencari dari tabel jabatan, sehingga uang makan, uang transport dan gaji pokok akan otomatis terisi), "Pilih" id absen karyawan sehingga izin, sakit, alpa, jumlah kehadiran akan otomatis terisi. Tombol "Cetak" digunakan untuk mencetak payslip. 


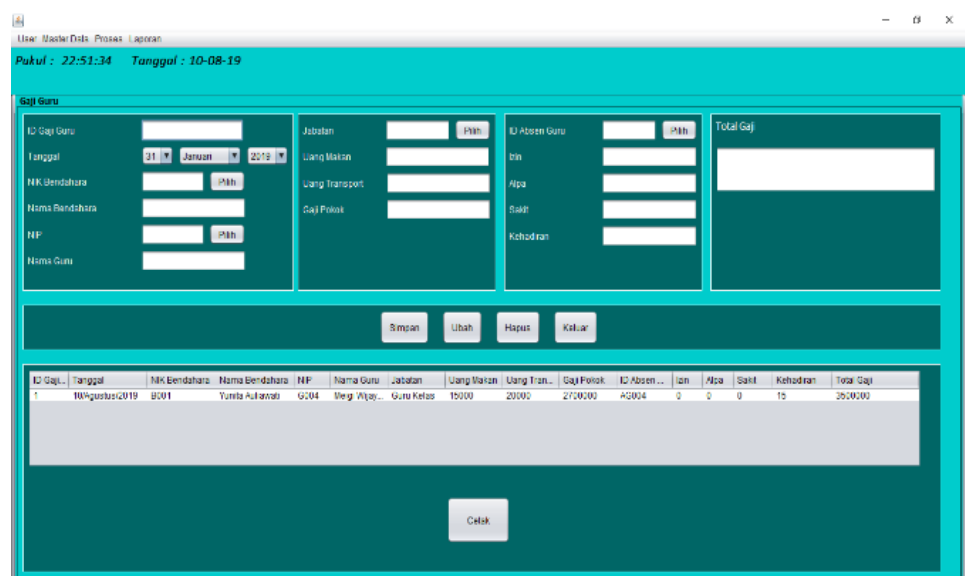

Gambar 8. Tampilan Form Gaji Guru

Tampilan form gaji guru, user dapat melakukan input data, mengubah, menghapus dan menampilkan data gaji guru. Terdapat inputan id gaji guru, tanggal, nik bendahara (klik button "Pilih" untuk mencari dari tabel bendahara, nama bendahara (akan otomatis terisi jika nik sudah dipilih), nik guru (klik button "Pilih" untuk mencari dari tabel guru) nama guru (otomatis terisi jika nik guru sudah dipilih), jabatan (klik button "Pilih" untuk mencari dari tabel jabatan, sehingga uang makan, uang transport dan gaji pokok akan otomatis terisi), "Pilih" id absen guru sehingga izin, sakit, alpa, jumlah kehadiran akan otomatis terisi berdasarkan table absen guru. Tombol "Cetak" digunakan untuk mencetak payslip.

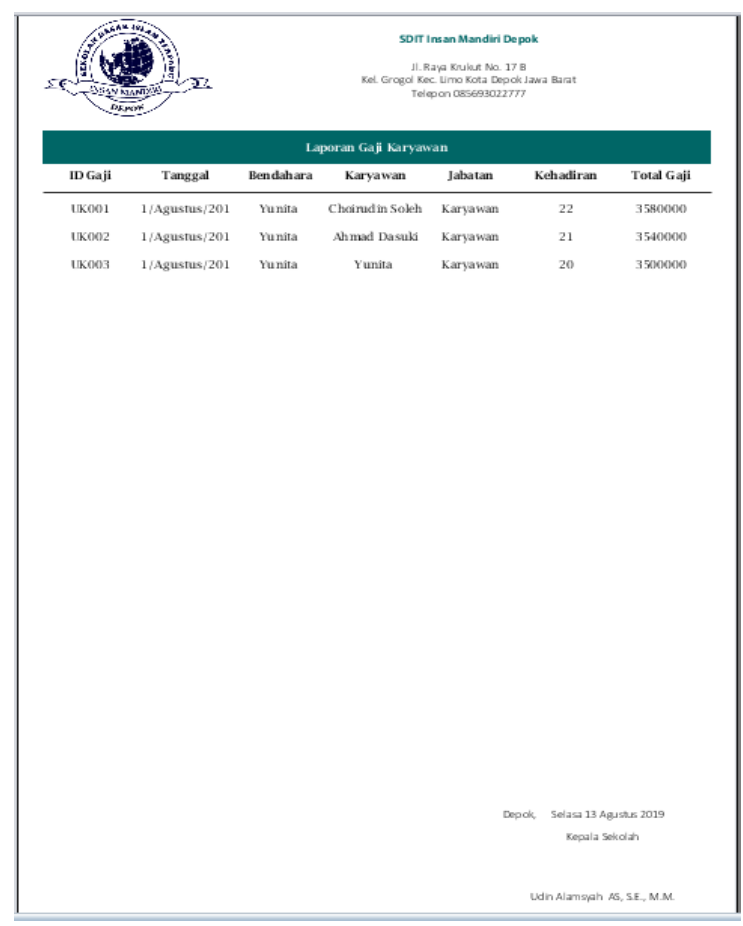

Gambar 9. Tampilan Laporan Gaji Karyawan

Rancangan laporan data gaji karyawan ini berisi data-data yang ada pada tabel gaji karyawan. Ini muncul ketika user mengklik tombol laporan gaji karyawan pada tampilan menu utama. User bisa mencetak laporan ini dengan mengklik tombol "Cetak". 


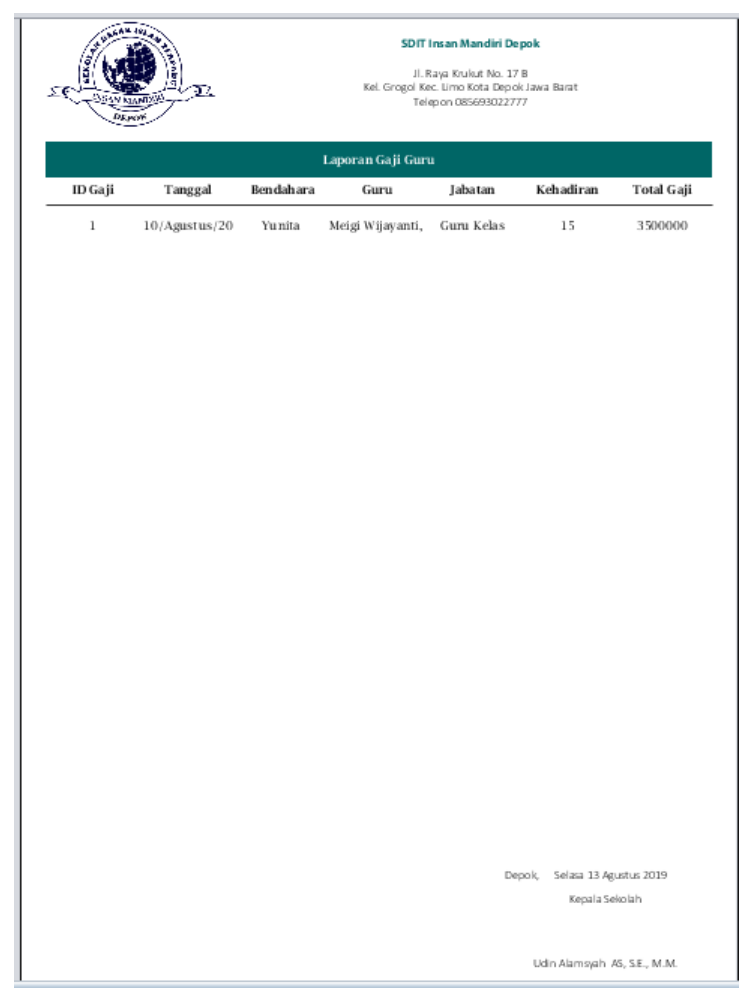

Gambar 10. Tampilan Laporan Gaji Guru

Rancangan laporan data gaji guru ini berisi data-data yang ada pada tabel gaji guru. Ini muncul ketika user mengklik tombol laporan data gaji guru pada tampilan menu utama. User bisa mencetak laporan ini dengan mengklik tombol "Cetak".

\section{SIMPULAN}

Berdasarkan analisa yang dilakukan, maka sistem penggajian guru dan karyawan di SDIT Insan Mandiri Depok dapat diterapkan dan menjadi salah satu solusi yang tepat bagi sekolah ini. Sehingga dapat diambil kesimpulan penggunaan sistem komputerisasi dapat membantu sekolah dalam mempercepat proses-proses pengolahan data sehingga kekurangan pada sistem yang lama dapat teratasi, memudahkan pelayanan khususnya di bagian tata usaha dan meningkatkan efisiensi dari berbagai kegiatan, mengurangi kesalahan-kesalahan yang sering dilakukan oleh manusia, pemrosesan dan penyajian informasi yang cepat, tepat dan akurat.

\section{DAFTAR PUSTAKA}

Haryadi, C., \& Arifin, R. W. (2016). Sistem Informasi Penggajian Karyawan Pada PT. White Horse Ceramic Indonesia. Bina Insani ICT Journal, 3 No. 2(ISSN : 2355 - 3421), 370-383.

Hermawan, T. D., \& Wardati, I. U. (2016). Perancangan Sistem Informasi Penggajian Pada Sekolah Menengah Pertama Negeri (SMPN) 3 Punung. Journal Speed - Sentra Penelitian Engineering Dan Edukasi, 8(ISSN : 1979-9330), 65-68.

Nurseha. (2016). Perancangan Sistem Aplikasi Penggajian Guru / Karyawan dan Administrasi pada TK Az-Zahra. Universitas Indraprasta PGRI.

Ramadhan, G. (2016). Perancangan Sistem Administrasi Penggajian Guru dan Karyawan di SDIT Al-Muhajirin Bogor. Universitas Indraprasta PGRI.

Saputra, A. W., \& Bukhori, I. (2014). Perancangan sistem informasi penggajian Pada Sekolah Menengah pertama (SMP) PGRI Kebonagung. Indonesian Journal on Networking and Security, 3 No. 3. 